\title{
Analisis Efektivitas Biaya Distribusi Lumpsum Terhadap Pendapatan (Studi Kasus di PT. Indofresh Cabang Jakarta)
}

\author{
Panca Rochman Fanus, lis Dewi Herawati \\ 1'2Fakultas Ekonomi dan Bisnis, Universitas Panca Sakti Bekasi
}

\begin{tabular}{l}
\hline ARTICLE INFO \\
\hline Article History: \\
Received 20 Oktober 2021 \\
Revised 15 Desember 2021 \\
Accepted 19 Desember 2021 \\
Published 30 Desember 2021
\end{tabular}

\section{Keywords:}

Biaya Distribusi;

Efisiensi;

Analisis;

Lumpsum;

Dampak.

\begin{abstract}
In the retail business, distribution costs as a major cost component that greatly affect a company's profit or loss. PT. Indofresh as the largest importer and distributor of fresh fruit and vegetable products in Indonesia that faces high distribution costs and also often late return letters as a means of billing has a severe impact on the company's financial activities. So the company carried out an efficiency initiative by changing the pattern of distribution costs from distribution costs paid upfront to lumpsum distribution costs applied in Jakarta. This research uses quantitative and qualitative methods. The purpose of this research will be to study the effectiveness and impact that will be caused by the application of these costs so that in the future it will be useful for companies for application in other branches or can be used in other companies. In the end, this study proves that efficiency can be achieved by applying lumpsum distribution costs can achieve efficiency of up to $20 \%$, proof of return letter or pod (proof of delivery) increases by more than 20\%, the process of billing credit sales and the effectiveness of the work of related parts becomes faster.
\end{abstract}

Dalam bisnis retail, biaya distribusi sebagai komponen biaya utama yang sangat mempengaruhi laba atau rugi perusahaan. PT. Indofresh selaku importir dan distributor produk-produk buah dan sayur segar terbesar di Indonesia yang menghadapi kondisi tingginya biaya distribusi dan juga sering terlambatnya surat jalan kembali sebagai sarana penagihan memberikan dampak berat bagi aktivitas keuangan perusahaan. Maka perusahaan melakukan inisiatif efisiensi dengan mengubah pola biaya distribusi dari biaya distribusi dibayar dimuka menjadi biaya distribusi lumpsum yang diterapkan dicabang Jakarta. Penelitian ini menggunakan metode kuantitatif dan kualitatif. Tujuan penelitian ini akan mempelajari efektivitas dan dampak yang akan ditimbulkan dari penerapan biaya ini sehingga kedepan akan berguna bagi perusahaan untuk penerapan di cabang lainnya atau dapat digunakan di perusahaan lainnya. Pada akhirnya, penelitian ini membuktikan bahwa efesiensi dapat dicapai dengan menerapkan biaya distribusi lumpsum dapat mencapai efisiensi hingga $20 \%$, bukti surat jalan kembali atau pod (prof of delivery) meningkat lebih dari $20 \%$, proses penagihan penjualan kredit dan efektifitas kerja bagian yang terkait menjadi lebih cepat.

\section{Corresponding Author:}

Panca Rochman Fanus,

Email: pancafk@yahoo.com

How to Cite: Fanus, P.R., Herawati, I.D. (2021). Analisis efektivitas biaya distribusi lumpsum terhadap pendapatan (studi kasus di PT. Indofresh Cabang Jakarta. Sosio e-Kons, 13 (03), 190-198 


\section{PENDAHULUAN}

Pada masa pendemi covid-19 seperti ini, dimana semua aktivitas usaha disegala sektor membuat ekonomi menjadi sulit, baik di tingkat nasional, regional maupun juga secara global. Artinya kesulitan ekonomi ini melanda secara global. Sangat terbatasnya akses masyarakat tentu akan memberikan dampak terhadap perputaran sendi-sendi ekonomi usaha. Pelaku usaha pun dituntut untuk lebih kreatif agar dapat bertahan dengan kondisi yang serba tidak pasti ini. Salah satu cara untuk dapat bertahan dari gelombang deskruktif ekonomi ini adalah pelaku usaha harus dapat melakukan efisiensi biaya dengan memangkas biaya atau inovasi-inovasi agar biaya menjadi lebih efisien.

Biaya distribusi adalah salah satu biaya operasional perusahaan yang menjadi faktor biaya terbesar dan akan mempengaruhi laba atau rugi dari aktivitas sebuah perusahaan. Hal ini dimungkinkan karena biaya distribusi menjadi penggerak dalam aktivitas usaha dimana seluruh biaya yang berhubungan dengan pembelian, penyimpanan, penawaran, pengepakan, pengiriman barang sampai ke pelanggan baik langsung maupun tidak langsung tercatat sebagai biaya.

Biaya menurut (Salman \& Farid, 2016) mendefinisikan biaya adalah biaya (kos) adalah kas atau nilai equivalen kas yang dikorbankan untuk mendapatkan barang atau jasa yang diharapkan memberi manfaat saat ini atau dimasa mendatang bagi organisasi.

Efisiensi menurut (Kbbi, 2016) dimaksudkan sebagai tepat atau sesuai untuk mengerjakan (menghasilkan) sesuatu (dengan tidak membuang-buang waktu, tenaga, biaya) dan juga dapat dimakasukdan mampu menjalankan tugas dengan tepat dan cermat; berdaya guna; bertepat guna; sangkil.

Distribusi diterjemahkan dari bahasa Inggis yaitu distribution yang berarti penyaluran. Berdasarkan kamus bahasa Inggris-Indonesia karya (Echols \& Shadily, 2019) bermakna membagikan, menyalurkan, menyebarkan, mendistribusikan, dan mengageni. Sedangkan menurut Kamus Besar Bahasa Indonesia, distribusi dimaksudkan sebagai penyalur (pembagian, pengiriman) kepada beberapa orang atau beberapa tempat. Menurut (Pujawan \& Er, 2017) distribusi adalah menghantarkan produk dari lokasi tempat produk tersebut diproduksi sampai tempat produk digunakan. Menurut (Sofjan, 2018) distribusi merupakan suatu lembaga yang memasarkan produk, yang berupa barang atau jasa dari produsen ke konsumen.

Pendapatan adalah balas jasa atau sejumlah uang yang diterima oleh seseorang ataupun badan usaha sebagai imbalan atas pekerjaanya. FASB SFAC No.6 menekankan pengertian pendapatan pada arus masuk penambahan lain atas aktiva suatu entitas atau penyelesaian kewajibankewajibannya atau kombinasi keduanya yang berasal dari penyerahan atau produksi barang, pemberian jasa atau kegiatan-kegiatan lain yang merupakan operasi inti. Dalam Hananto dikutip dalam (Lawani et al., 2021) menuliskan bahwa pendapatan adalah kenaikan atau bertambahnya aset dan penurunan atau berkurangnya liabilitas perusahaan yang merupakan akibat dari aktivitas operasi atau pengadaan barang dan jasa kepada masyarakat atau konsumen pada khususnya.

PT. Indofresh adalah perusahaan importir dan disributor buah dan sayur segar terbesar di Indonesia dimana buah dan sayur segar adalah produk yang sangat unik sehingga penanganan aktivitasnya menjadi sangat unik pula. Keunikan ini terjadi karena buah dan sayur adalah produk musiman sehingga hanya tersedia pada musim-musim panen atau pada waktu-waktu tertentu saja. Buah dan sayur juga produk alam sehingga tidak ada standar khusus dan pasti atas kualitasnya. Buah dan sayur juga memiliki masa kadaluarsa yang sangat pendek yaitu antara 4 hari sampai 25 hari, selain itu dalam proses penyimpanan dan pengiriman dibutuhkan suhu khusus yaitu 0'c sampai dengan 4'c. Dengan beberapa keunikan tersebut, maka proses penanganan dan distribusi buah dan sayur dibutuhkan kecepatan dan ketepatan.

PT. Indofresh cabang Jakarta merupakan cabang terbesar dengan porsi $70 \%$ dibandingkan cabang lain mempunyai peran yang sangat penting dalam menggerakkan roda perusahaan. Segala bentuk keuntungan maupun kerugian akan sangat berdampak pada kelangsungan dan perkembangan perusahaan. Dalam hal ini, termasuk biaya distribusi yang menjadi beban utama dalam perusahaan. 
Karena itu, aktivitas distribusi barang yang disertai dengan timbulnya biaya distribusi tersebut harus dapat di analisa dengan cermat sehingga dapat memberikan konstribusi yang positif dalam menjaga kelangsungan perusahaan.

Berdasarkan data penelitian, penulis menemukan beberapa masalah besar dalam penerapanan skema biaya distribusi yang sudah dijalankan oleh perusahaan selama ini. Masalah-masalah tersebut yaitu:

1. Borosnya penggunaan bbm truk, dimana truk CDE yang standard pemakaian bbm untuk 1-liter solar dapat menempuh jarak $7 \mathrm{~km}$ sampai $8 \mathrm{~km}$ tapi dalam prakteknya hanya dapat menempuh jarak $3 \mathrm{~km}$ sampai dengan $4 \mathrm{~km}$ per liter. Keborosan pemakaian bbm ini juga memberikan indikasi adanya penyalahgunaan atau pencurian bbm solar tapi sulit dibuktikan karena belum ditemukan metode yang tepat dalam malakukan pengecekan dan juga mengingat tingginya tingkat pengiriman ke pelanggan.

2. Kasir kesulitan dalam melakukan pengajuan anggaran pengisian kas kecil ke bagian keuangan karena sopir yang seharusnya melampirkan bukti kertas tol, bukti parkir, bukti restribusi justru sering tidak dilampirkan bahkan beberapa ada yang hilang. Kesulitan tersebut membuat kasir membutuhkan waktu lebih untuk meminta dokumen ke sopir.

3. Waktu pengiriman menjadi terlambat karena banyak sopir yang meminta lebih atas uang jalan sebagai antisipasi jika ada biaya lain-lain. Hal ini menimbulkan perdebatan dengan petugas kasir dengan sopir sehingga menimbulkan waktu tambahan yang menghambat proses pengiriman.

4. Banyak bukti tagihan bongkar yang tidak wajar karena bukti bayar manual dan tidak standar sehingga menimbulkan celah adanya penyalahgunaan dan penyelewangan oleh sopir.

5. Terhambatnya proses penagihan dan juga adanya potensi tidak tertagihnya penjualan kredit karena surat jalan kembali sebagai bukti pengiriman dan untuk proses penagihan ke pelanggan sering terlambat bahkan hilang.

Dengan masalah-masalah dan potensi kerugian yang ada tersebut diatas, maka pihak manajemen berusaha merumuskan, menetapkan dan menerapkan kebijakan baru agar efisiensi biaya distribusi dapat tercapai.

\section{METODE}

Dalam jurnal ini, penulis menggunakan metode kuantitatif dan kualitatif yaitu melalui pengumpulan data-data primer, sekunder, observasi dan wawancara dengan dengan beberapa narasumber untuk mendapatkan gambaran dan informasi yang diharapkan dapat memberikan hasil yang lebih obyektif.

\section{HASIL DAN PEMBAHASAN}

\section{Identifikasi Biaya Distribusi}

Dalam operasional untuk melakukan distribusi barang, maka timbul biaya distribusi seperti biaya transportasi bbm, biaya tol, biaya bongkar, biaya parkir, biaya retribusi, biaya insentif sopir, dll. Pada studi kasus di PT. Indofresh cabang Jakarta, biaya distribusi yang timbul sebelumnya telah ditentukan dan tetapkan dalam aturan perusahaan. Adapun biaya-biaya tersebut selama ini dibayarkan dengan beberapa metode yaitu:

1. Biaya transportasi bbm adalah biaya yang digunakan untuk pembelian bbm jenis solar yang digunakan untuk mengisi tangki bbm truk dimana perusahaan telah menggunakan kartu bbm yang telah bekerjasama dengan spbu terdaftar. Pembayaran bbm ini sifatnya adalah deposit perusahaan yang akan mengurangi saldo deposit setiap pembelian bbm solar di spbu terdaftar. 
2. Biaya tol adalah biaya yang timbul atas penggunaan akses tol oleh sopir truk dalam mengantarkan barang ke pelanggan. Perusahaan telah menyediakan kartu tol yang dapat di isi ulang setiap saat oleh staf administrasi di kantor.

3. Biaya bongkar adalah biaya yang timbul atas proses bongkar barang dari truk ke toko pelanggan dengan nilai yang ditagihkan per jumlah karton yang dibongkar oleh petugas kuli bongkar muat di area pelanggan. Untuk pemakaian jasa ini, maka sopir membayar dan akan diberikan bukti bayar yang akan ditagihkan ke perusahaan.

4. Biaya parkir adalah biaya yang timbul atas parkir truk selama parkir di area pelanggan yang biasanya berlokasi di pasar-pasar, mall atau ruko. Untuk pemakaian jasa parkir ini, maka sopir membayar dan akan diberikan bukti bayar yang akan ditagihkan ke perusahaan.

5. Biaya restribusi adalah biaya yang timbul saat melintasi jalan-jalan atau area-area tertentu baik sifatnya resmi ataupun tidak resmi. Untuk biaya ini, maka sopir membayar dan akan diberikan bukti bayar yang akan ditagihkan ke perusahaan.

6. Biaya insentif adalah biaya yang diberikan kepada sopir atas pencapaian pengiriman yang dihitung berdasaran per titik pengiriman yang dilakukan dan dibayarkan setiap bulan bersamaan dengan pembayaran gaji bulanan.

Seluruh komponen biaya diatas kecuali biaya insentif, akan dibayarkan dimuka oleh kasir sebelum sopir berangkat mengantarkan barang ke pelanggan, dan akan dikembalikan sore atau malam hari bersama dengan kembalinya surat jalan yang sudah ditandatangani sebagai bukti penerimaan barang oleh pelanggan. Sedangkan biaya insentif dibayarkan terpisah dan diakumulasikan setiap bulan untuk dibayarkan bersamaan dengan pembayaran gaji sopir.

Untuk menunjang pembahasan materi, maka dibawah ini kami sajikan tabel pendapatan dan biaya distribusi perusahaan sebagai berikut:

Tabel 1.

Laporan Pendapatan dan Biaya Distribusi

\begin{tabular}{lrr}
\hline \multicolumn{1}{c}{ Akun } & \multicolumn{1}{c}{2017} & \multicolumn{1}{c}{2018} \\
\hline Pendapatan & 707.985 .443 .148 & 67.913 .545 .376 \\
Biaya BBM - Operasional & 1.161 .545 .316 & 931.365 .048 \\
Biaya Transportasi & 47.175 .600 & 83.994 .000 \\
Biaya Tol, Parkir Kendaraan & 890.172 .000 & 727.456 .680 \\
Biaya Angkut Penjualan & 115.500 .000 & 1.037 .400 .000 \\
Biaya Upah Bongkar muat & 494.510 .100 & 276.629 .100 \\
Biaya Insentif Driver & 274.440 .000 & 281.100 .000 \\
Total Biaya & 2.983 .343 .016 & 3.337 .944 .828 \\
Jumlah Karton Yang Dikirim & 2.254 .428 & 1.977 .184 \\
Biaya Operasional per Bulan per & 1.323 & 1.688 \\
Karton & Sumber: laporan pendapatan biaya perusahaan
\end{tabular}

\section{Identifikasi Biaya Distribusi Lumpsum}

Lumpsum menurut (KBBI, 2016) Kamus Besar Bahasa Indonesia adalah uang yang dibayarkan sekaligus untuk biaya transpor, uang makan, dan sebagainya. Sehingga biaya operasional lumpsum adalah biaya-biaya yang timbul karena aktivitas pengiriman barang dari perusahaan ke pelanggan yang dibayarkan sekaligus. Dalam menentukan nilai biaya lumsum, maka perlu dijelaskan proses penentuan biayanya adalah sebagai berikut:

1. Menentukan dan mengklasifikasikan dalam grup area atas titik alamat kirim pelanggan. 
2. Biaya transportasi bbm solar. Biaya ini dihitung berdasarkan rata-rata pemakaian bbm solar pada jarak rata-rata yang ditempuh per area.

3. Biaya tol. Biaya ini dihitung berdasarkan tol yang dilalui pada jarak rata-rata yang ditempuh per area.

4. Biaya bongkar muat. Biaya ini dihitung berdasarkan rata-rata biaya bongkar per area, kecuali pelanggan khusus yang disertai daftar tarip resmi, ini akan dibayar penuh sesuai dengan tagihan.

5. Biaya parkir. Biaya ini dihitung berdasarkan rata-rata pembayaran parkir pada area tersebut.

6. Biaya restribusi. Biaya ini dihitung berdasarkan rata-rata pembayaran restribusi pada area tersebut.

7. Biaya insentif. Biaya ini dihitung berdasarkan rata-rata biaya insentif yang dibayarkan per bulan susuai dengan output atau jumlah karton yang dijual.

Setelah melakukan analisa dan perhitungan dengan skema seperti diatas, maka pihak manajemen menetapkan biaya lumpsum di cabang Jakarta sesuai adalah sebagai berikut:

Tabel 2.

Tarif Biaya Distribusi Lumsum

\begin{tabular}{ccccc}
\hline \multirow{2}{*}{ Zona } & Area Kirim & \multicolumn{3}{c}{ Jenis Kendaraan } \\
\cline { 3 - 5 } & Jakarta, Bekasi, Cibitung, Cikarang & Rp.150.000 & RDE.200,000 & Rp.250.000 \\
\hline 1 & Bogor, Tangerang, Tangerang Selatan, Karawang & Rp.200.000 & Rp.250.000 & Rp.300.000 \\
3 & Serang, Cilegon & Rp.0 & Rp.400.000 & Rp.500.000 \\
4 & Bandung & Rp.0 & Rp.500.000 & Rp.600.000 \\
\hline
\end{tabular}

Sumber: dokumen laporan biaya perusahaan

Untuk menunjang pelaksanaan biaya distribusi lumpsum tersebut, perusahaan juga memperbaiki peraturan pembayaran sebagai berikut:

1. Kasir hanya melakukan pembayaran saat dokumen surat jalan lengkap. Arti lengkap disini adalah diterima dengan bukti yang sah dan dapat dipertanggunjawakan oleh pelanggan untuk memudahkan proses penagihan.

2. Kasir melakukan pembayaran pada saat sopir kembali bukan dibayar dimuka pada saat sopir akan berangkat.

Berdasarkan data atas penerapan biaya distribusi lumsum pada periode tahun 2019 dan tahun 2020, maka biaya per karton yang timbul adalah seperti pada tabel sebagai berikut:

Tabel 3.

Laporan Pendapatan dan Biaya Distribusi Lumpsum

\begin{tabular}{ccc}
\hline Akun & 2019 & 2020 \\
\hline Pendapatan & 1.112 .730 .302 .808 & 954.313 .188 .000 \\
Biaya BBM - Operasional & 0 & 0 \\
Biaya Transportasi & 2.654 .593 .200 & 2.416 .116 .000 \\
Biaya Tol, Parkir Kendaraan & 0 & 0 \\
Biaya Angkut Penjualan & 0 & 0 \\
Biaya Upah Bongkar muat & 326.880 .300 & 245.290 .200 \\
Biaya Insentif Driver & 0 & 0 \\
Total Biaya & 2.981 .473 .500 & 2.661 .406 .200 \\
Jumlah Karton Yang Dikirim & 3.714 .532 & 3.004 .608 \\
Biaya Operasional per Bulan per & 803 & 886 \\
Karton & &
\end{tabular}

Sumber: dokumen laporan pendapatan dan biaya perusahaan 


\section{Pembahasan}

\section{a. Analisa Biaya Distribusi terhadap Pendapatan}

Untuk melakukan analisa efektifitas biaya distribusi terhadap pendapatan maka perlu dilakukan perhitungan dengan rumus sebagai berikut:

$$
\mathrm{E}=\frac{o}{\mathrm{i}} \times 100 \%
$$

Dimana:

$E=$ Efisiensi

0 = output atau biaya yang dikeluarkan

$\mathrm{i}=$ input atau masukan atau pendapatan

Tabel 4.

Kreteria Pengukuran Efisiensi

\begin{tabular}{cc}
\hline Rasio Efisiensi & Kreteria \\
\hline$<20 \%$ & Sangat Efisien \\
$21 \%-85 \%$ & Efisien \\
$>85 \%$ & Tidak Efisien
\end{tabular}

Biaya distribusi untuk periode tahun 2017

Diketahui:

$0=$ Rp.707.985.443.148

$\mathrm{i}=\mathrm{Rp} \cdot 2.983 .343 .016$

$$
\mathrm{E}=\frac{707.985 .443 .148}{2.983 .343 .016} \times 100 \%=42 \%
$$

Biaya distribusi untuk periode tahun 2018

Diketahui:

$0=$ Rp.767.913.545.376

$\mathrm{i}=\operatorname{Rp} \cdot 3 \cdot 337.944 .828$

$$
\mathrm{E}=\frac{767.913 .545 .376}{3.337 .944 .828} \times 100 \%=43 \%
$$

Biaya distribusi untuk periode tahun 2019

Diketahui:

$0=$ Rp.1.112.730.302.808

$\mathrm{i}=\mathrm{Rp} \cdot 2.981 .473 .500$

$$
\mathrm{E}=\frac{1.112 .730 .302 .808}{2.981 .473 .500} \times 100 \%=27 \%
$$

Biaya distribusi untuk periode tahun 2020

Diketahui:

$0=$ Rp.954.313.188.000

$\mathrm{i}=\mathrm{Rp} \cdot 2 \cdot 661.406 .200$ 


$$
\mathrm{E}=\frac{954.313 .188 .000}{2.661 .406 .200} \times 100 \%=28 \%
$$

Berdasarkan data perhitungan diatas maka biaya distribusi mengalami peningkatan efisiensi dari rasio $42 \%$ sampai dengan $43 \%$ menjadi $27 \%$ sampai dengan $28 \%$. Peningkatan efisiensi $20 \%$ setelah diterapkan biaya distribusi dibandingkan sebelumnya sangat memberikan dampak positif dan signifikan terhadap pendapatan. Jika dihitung rata-rata penjualan dalam karton per bulan dengan asumsi 200.000 karton, maka biaya distribusi yang sebelumnya dikeluarkan akan mencapai Rp.264 juta sampai dengan Rp.337 juta. Sedangkan dengan penerapan biaya distribusi lumsum ini dapat memberikan efisiensi biaya distribusi rata-rata sebesar Rp.104 juta sampai Rp.160 juta. Ini tentu merupakan sangat kontribusi positif dan sangat besar bagi pendapatan perusahaan.

Tabel 5.

Tingkat Efisiensi Biaya Distribusi

\begin{tabular}{cccl}
\hline Tahun & Biaya Distribusi & Rasio Efisiensi & Kreteria \\
\hline 2017 & Dibayar Dimuka & $42 \%$ & Efisien \\
2018 & Dibayar Dimuka & $43 \%$ & Efisien \\
2019 & Lumpsum & $27 \%$ & Efisien \\
2020 & Lumpsum & $28 \%$ & Efisien \\
\hline
\end{tabular}

\section{b. Analisa Biaya Distribusi per Karton}

Jika dibandingkan antara biaya distribusi sebelum dan sesudah diterapkan metode lumsum maka dapat diketahui bahwa metode lumpsum dapat memberikan biaya per karton yang lebih rendah dibandingkan sebelumnya yaitu penurunan biaya distribusi per karton sekitar $41 \%$ sampai dengan $47 \%$ atau Rp.803 per karton sampai dengan Rp.886 per karton, sementara biaya distribusi sebelumnnya adalah Rp.1.323 per karton sampai dengan Rp.1.688 per karton dalam bentuk gambar grafik adalah sebagai berikut:

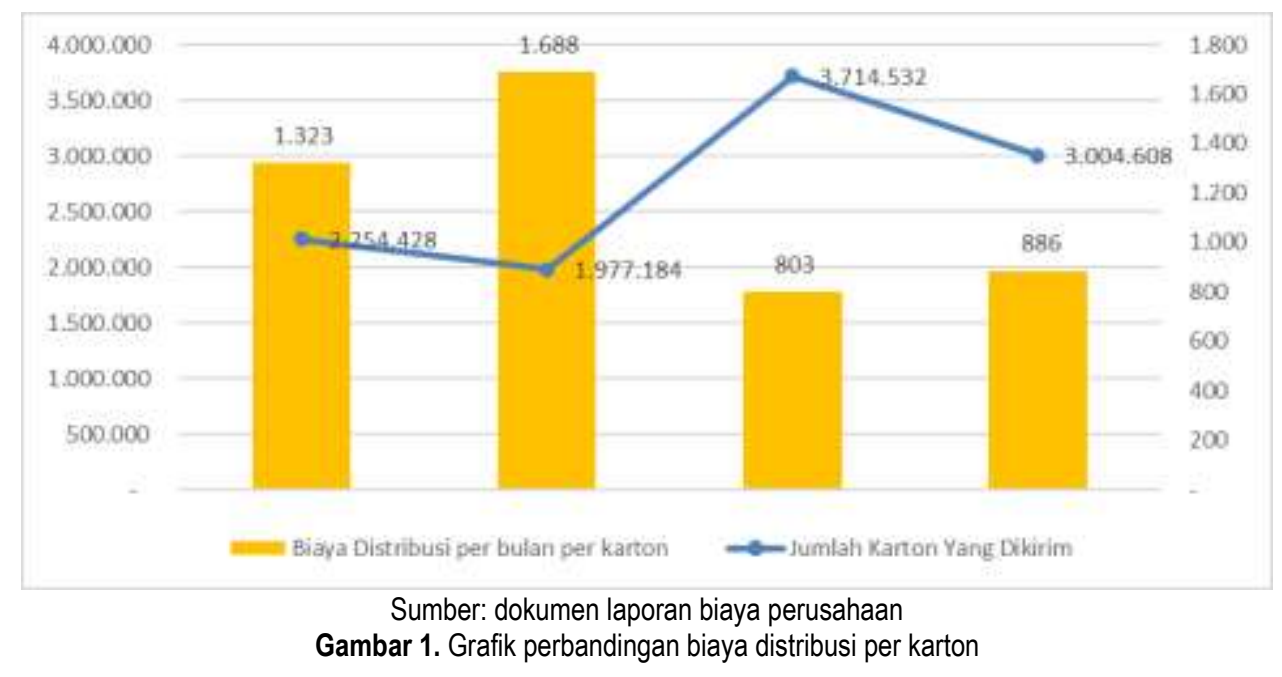

\section{c. Analisa Biaya Distribusi Lumpsum Pengaruhnya terhadap Surat Jalan Kembali}

Berdasarkan data POD (proof of delivery) atau surat jalan kembali menunjukkan bahwa sebelum diberlakukan biaya distribusi lumpsum rata-rata prosentase surat jalan kembali adalah $73 \%$ sampai dengan $79 \%$ sedangkan setelah dilakukan biaya distribusi lumpsum rata-rata prosentase surat jalan kembali adalah 91\% sampai dengan $92 \%$. Diagram surat jalan kembali ditunjukkan dengan gambar 2 sebagai berikut: 


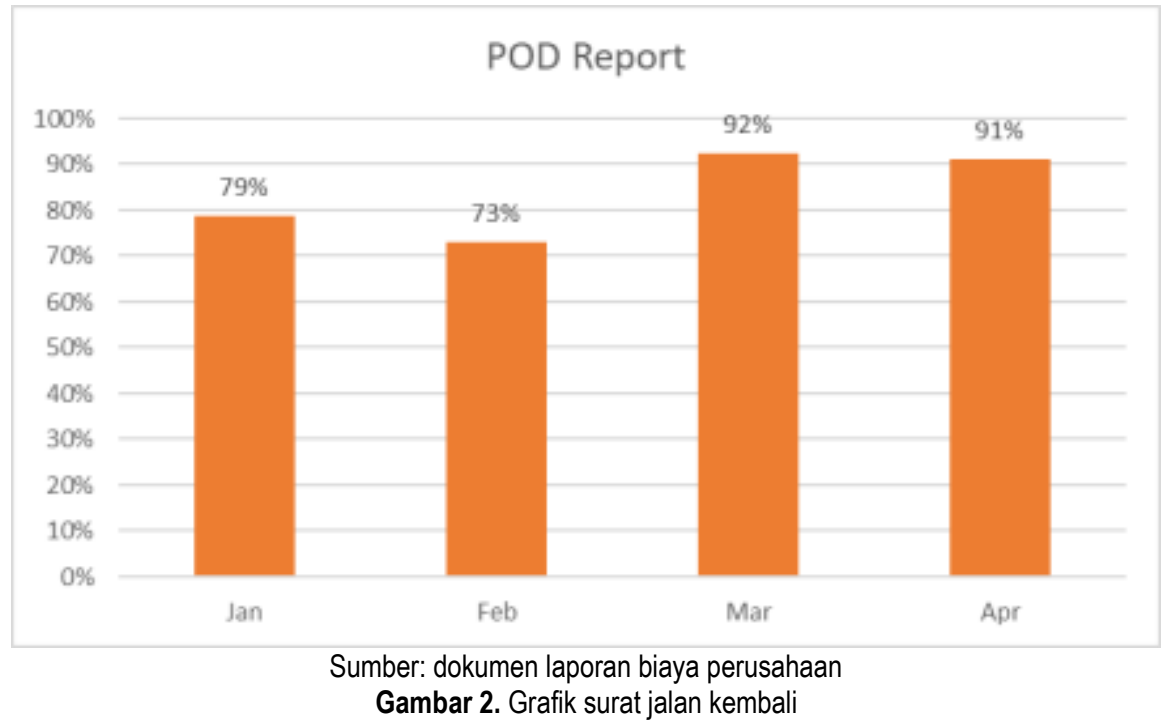

\section{SIMPULAN DAN SARAN}

Berdasarkan data tersebut diatas, maka dapat disimpulkan bahwa penetapan dan penerapan biaya distribusi lumsum memberikan dampak lebih efisien dari segi biaya karena memberikan efisiensi hingga $20 \%$ dibandingkan dengan biaya distribusi dibayar dimuka, selain itu dampak positif yang dihasilkan dari penerapan ini adalah bukti surat jalan kembali atau pod (prof of delivery) meningkat lebih dari $20 \%$ sehingga pencapaian bukti surat jalan kembali menjadi $90 \%$. Peningkatan ini tentu akan sangat berdampak pada proses penagihan penjualan kredit dimana dengan dokumen tersebut maka proses penagihan telah lengkap di awal dan proses penagihan menjadi lebih cepat, selain itu akan meminimalisasi potensi kehilangan surat jalan yang pernah terjadi pada periode sebelumnya. Proses perhitungan yang lebih sederhana juga akan memudahkan dan mempercepat kasir dalam proses pembayaran kepada para sopir sehingga ini juga akan mempercepat proses pengecekan ulang bagi kasir, mengurangi antrian sopir dikasir, dan juga mempermudah dan mempercepat proses pengisian ulang kas kecil.

Peningkatan ini juga dirasakan oleh para sopir karena sopir menjadi lebih mudah dan cepat dalam proses perhitungan. Adakalanya, sopir mampu mendapatkan pendapatan yang lebih jika mampu menghemat pengeluarannya. Sehingga penerarapan biaya distribusi ini adalah solusi tepat bagi semuanya baik sopir, kasir, bagian penagihan dan perusahaan secara umum karena membantu mempercepat penagihan penjualan kredit dan juga mengehemat biaya pengeluaran.

Dengan efisiensi yang dampak positifnya dirasakan oleh perusahaan baik secara biaya, kecepatan proses penagihan dan juga kecepatan proses pengisian kas kecil serta juga dirasakan oleh sopir, maka tentu metode biaya distribusi lumsum sangat tepat untuk diterapkan baik di PT. Indofresh cabang Jakarta dan dapat diterapkan selanjutnya untuk cabang-cabang lainnya ataupun untuk perusahaan lain yang mengalami kendala dan masalah yang sama sehingga perusahaan yang menerapkan metode ini akan memberikan efek positif secara ganda.

\section{REFERENCES/DAFTAR PUSTAKA}

Echols, J. M., \& Shadily, H. (2019). Kamus inggris indonesia. Gramedia. Jakarta.

Kbbi, K. (2016). Kamus Besar Bahasa Indonesia (KBBI). Kementerian Pendidikan Dan Budaya. 
Lawani, P., Pangemanan, S. S., \& Kalalo, M. Y. B. (2021). Analisis perbandingan pendapatan usaha kopra putih dengan menggunakan pengolahan oven dan solar dryer dome di umkm jr agro indonesia. Going concern: jurnal riset akuntansi, 16(4), 323-334.

Pujawan, I. N., \& Er, M. (2017). Supply chain management edisi 3. Guna Widya, Surabaya.

Salman, K. R., \& Farid, M. (2016). Akuntansi manajemen. In Indeks. Jakarta. Penerbit Indeks Jakarta.

Sofjan, A. (2018). Manajemen Bisnis Pemasaran. Raja Grafindo. Jakarta. 